\title{
HUBUNGAN INFESTASI CACING YANG DITULARKAN MELALUI TANAH DAN EOSINOFILIA PADA SISWA SD GMIM BUHA MANADO
}

\author{
${ }^{1}$ Yeti Teresia Matei \\ ${ }^{2}$ Novie Rampengan \\ ${ }^{2}$ Sarah M. Warouw
}

\author{
${ }^{1}$ Kandidat Skripsi Fakultas Kedokteran Universitas Sam Ratulangi Manado \\ ${ }^{2}$ Bagian Ilmu Kesehatan Anak Fakultas Kedokteran Universitas Sam Ratulangi Manado \\ Email: yeti.matei@yahoo.com
}

\begin{abstract}
Infestation of soil transmitted helminth is often found among communities in developing countries. This helminthic infestation can affect nutritional state, physical growth, mental, cognition, and intellectual deterioration in children. Increased eosinophils (eosinophilia) is often associated with diseases caused by worms and allergy. This study aimed to determine the links between investastion of soil transmitted helminth and esinophilia among students in SD GMIM Buha Manado. This was a prospective observational study with a cross-sectional approach. According to exclusive and inclusive criteria, 80 samples were obtained. Data were analyzed by using the Fisher Exact and Phy correlation coefficient analysis. The resluts showed that $17.5 \%$ students were infected by Ascaris lumbricoides, meanwhile Trichuris trichiura and hookworm were not evident. The corelation test showed that there was a significant relationship between infestation of soil transmitted helminth and eosinophilia with a $P$-value $=0.001$. Conclusion: There was a high significant relationship between infestation of soil transmitted helminth and eosinophilia among students of SD GMIM Buha Manado. The most frequent found was Ascaris lumbricoides and its infestation was marked by eosinophilia.
\end{abstract}

Keywords: Soil transmitted helminth, eosinophilia, students of SD GMIM Buha Manado.

\begin{abstract}
Abstrak: Infestasi cacing yang ditularkan melalui tanah banyak ditemukan pada masyarakat di negara berkembang. Infestasi cacing bisa berdampak terhadap gizi, pertumbuhan fisik, mental, kognitif, dan kemunduran intelektual pada anak. Peningkatan eosinofil sering dikaitkan dengan penyakit yang disebabkan oleh cacing dan alergi. Penelitian ini bertujuan untuk mengetahui hubungan infestasi cacing yang ditularkan melalui tanah dan eosinofilia pada siswa SD GMIM Buha Manado. Penelitian ini merupakan penelitian prospektif observasional dengan pendekatan potong lintang.cross - sectional. Berdasarkan kriteria eksklusi dan inklusi diperoleh 80 sampel. Analisis korelasi yang digunakan ialah uji Fisher Exact dan analisis koefisien korelasi Phi. Hasil penelitian memperlihatkan 17,5\% siswa terinfestasi cacing Ascaris lumbricoides, sedangkan Trichuris trichiura dan cacing tambang tidak ditemukan. Hasil uji korelasi menunjukkan bahwa terdapat hubungan yang sangat bermakna antara infestasi cacing yang ditularkan melalui tanah dan eosinofilia dengan $P=$ 0,001 . Simpulan: Terdapat hubungan yang sangat bermakna antara infestasi cacing yang ditularkan melalui tanah dan eosinofilia Cacing yang paling banyak menginfestasi siswa SD GMIM Buha Manado ialah Ascaris lumbricoides. Adanya infestasi Ascaris lumbricoides ditandai dengan peningkatan eosinofil.
\end{abstract}

Kata Kunci: Infestasi cacing yang ditularkan melalui tanah, eosinofilia, siswa SD GMIM Buha Manado. 
Infestasi cacing merupakan salah satu penyakit yang paling umum tersebar dan menjangkiti masyarakat di seluruh dunia. Rendahnya mutu sanitasi menjadi penyebabnya. ${ }^{1}$ Infestasi cacing bisa berdampak terhadap gizi, pertumbuhan fisik, mental, kognitif, dan kemunduran intelektual pada anak-anak. $^{2}$

Infestasi cacing yang disebabkan oleh cacing yang ditularkan melalui tanah atau soil transmitted helminth (STH) banyak ditemukan pada masyarakat di negara berkembang. Empat spesies STH yang paling sering ditemukan pada anak-anak yaitu cacing gelang (Ascaris lumbricoides), cacing cambuk (Trichuris trichiura) dan cacing tambang (Necator americanus dan Ancylostoma duodenale). Soil transmitted helminth adalah nematoda yang dalam siklus hidupnya untuk mencapai stadium infektif memerlukan tanah dengan kondisi tertentu. ${ }^{3}$

Di seluruh dunia terdapat sekitar 300 juta penduduk dengan infestasi cacing yang berat dan sekitar 150.000 kematian terjadi setiap tahun akibat infestasi STH. ${ }^{2}$ Infestasi cacing yang diakibatkan oleh STH merupakan salah satu penyakit yang masih menjadi masalah kesehatan di Indonesia. Dari hasil survei tahun 2008 yang dilakukan pada siswa sekolah dasar di 8 provinsi di Indonesia, infestasi STH mempunyai nilai yang cukup tinggi yaitu antara 2,7$60,7 \%$. Prevalensi infestasi cacing di provinsi Nanggroe Aceh Darussalam 59,2\%, Sumatra Barat 10,1\%, Banten 60,7\%, Jawa Barat 6,7\%, Kalimantan Barat 26,2\%, Kalimantan Tengah 5,3\%, Sulawesi Utara 2,7\%, dan Nusa Tenggara Timur 27,7\%. ${ }^{4}$

Penelitian mengenai infestasi cacing telah dilakukan dibeberapa sekolah dasar di Manado. Penelitian pada siswa SD di Kecamatan Tuminting menemukan 43,6\% siswa yang terinfestasi STH. Distribusi jenis infestasi cacing pada penelitian tersebut memperlihatkan bahwa infestasi tunggal 41,9\% dan infestasi campuran 20,5\%. ${ }^{5}$ Di SD GMIM Lahai Roy Malalayang didapatkan 11,25\%, dengan prevalensi spesies cacing terbanyak
Trichuris trichiura (77,78\%), kemudian Ascaris lumbricoides (22,22\%). ${ }^{6}$

Beberapa studi telah menunjukkan hubungan eosinofilia dengan infestasi cacing. Peningkatan eosinofil sering dikaitkan dengan penyakit yang disebabkan oleh cacing dan alergi. ${ }^{7}$ Eosinofilia merupakan penanda umum adanya infestasi cacing dan telah lama diduga bahwa sel tersebut sitotoksik dan diperlukan pada destruksi patogen multisel yang berukuran besar. ${ }^{8}$ Terdapat 2-5\% eosinofil dalam sel darah putih orang sehat yang tidak alergi. ${ }^{9} \mathrm{Di}$ Amerika, pemeriksaan eosinofil dilakukan untuk mengidentifikasi infestasi cacing pada pengungsi anak-anak. ${ }^{10}$ Studi di Filipina menunjukkan bahwa 58\% siswa dengan eosinofilia, 65\% telah didiagnosis adanya infestasi STH, dimana siswa yang terinfestasi lebih dari satu jenis cacing memiliki eosinofil yang lebih tinggi dibanding siswa yang terinfestasi satu jenis cacing. ${ }^{7}$ Di Manado, penelitian mengenai hubungan infestasi cacing dengan eosinofilia masih kurang diteliti.

Berdasarkan latar belakang di atas, penulis tertarik untuk melakukan penelitian untuk mengetahui hubungan infestasi cacing yang ditularkan melalui tanah dan eosinofilia pada siswa SD. Sekolah Dasar GMIM Buha merupakan lokasi yang dipilih untuk dilakukan penelitian ini. Pertimbangan pemilihan lokasi ini karena sekolah ini berada dekat dengan wilayah tempat pembuangan sampah dimana kebersihan lingkungannya buruk dan bisa mendukung siklus hidup STH.

\section{METODE PENELITIAN}

Penelitian ini menggunakan metode prospektif observasional analitik dengan pendekatan potong lintang. Penelitian dilakukan di SD GMIM Buha Manado dan Laboratorium Klinik Manado selama bulan November 2012. Kriteria inklusi yaitu terdapat persetujuan dari orang tua untuk mengikuti penelitian dengan menandatangani informed consent dan siswa yang terambil sampel feses dan darahnya. 
Kriteria eksklusi yaitu siswa yang tidak kooperatif saat dilakukannya pemeriksaan, serta siswa yang menderita penyakit alergi dan penyakit kulit.

Populasi berjumlah 175 siswa. Berdasarkan kriteria inklusi dan eksklusi diperoleh sampel sebanyak 80. Sampel dinyatakan terinfestasi bila pada pemeriksaan feses ditemukan telur atau cacing Ascaris lumbricoides, Trichuris trichiura dan cacing tambang (Necator americanus dan Ancylostoma duodenale). Eosinofilia didefinisikan sebagai keberadaan $>500$ eosinofil $/ \mu \mathrm{L}$ darah atau dalam hitung sel darah putih (WBC) terdapat $>7 \%$ eosinofil dari total leukosit. ${ }^{11,12}$ Siswa yang tidak terinfestasi STH diasumsikan tidak memiliki eosinofilia. Sampel feses diperiksa dengan teknik pewarnaan eosin. Analisis korelasi dengan menggunakan uji Fisher Exact dan analisis koefisien korelasi Phi.

\section{HASIL PENELITIAN}

Jumlah seluruh siswa SD GMIM Buha 175 siswa. Berdasarkan kriteria inklusi dan eksklusi didapatkan 80 siswa yang menjadi sampel. Siswa yang menjadi sampel berusia 6-13 tahun. Dari jumlah sampel yang diperiksa terdapat 58,8\% (47 siswa) berjenis kelamin perempuan dan 41\% (33 siswa) berjenis kelamin laki-laki. Berdasarkan penilaian status gizi, terdapat 83,8\% (67 siswa) status gizi normal, 3,8\% (3 siswa) status gizi kurang, 1,3\% (1 siswa) status gizi buruk, 8,8\% (7 siswa) status gizi lebih, dan 2,5\% (2 siswa) status gizi obesitas.

\section{Hasil Pemeriksaan}

Tabel 1. Hasil Pemeriksaan Feses Dari 80 Sampel yang Diperiksa

\begin{tabular}{lc}
\hline \multicolumn{1}{c}{ Infestasi STH } & N (\%) \\
\hline Tidak terinfestasi & $66(82,5 \%)$ \\
Terinfestasi Ascaris & $14(17,5 \%)$ \\
lumbricoides & \\
Terinfestasi Trichuris trichiura & - \\
Terinfestasi cacing tambang & - \\
\multicolumn{1}{c}{ N (\%) } & $80(100 \%)$ \\
\hline
\end{tabular}

Pada tabel 1 dapat dilihat bahwa infestasi STH paling banyak disebabkan oleh Ascaris lumbricoides, sedangkan spesies lain tidak ditemukan.

Tabel 2. Eosinofilia pada infestasi cacing yang ditularkan melalui tanah

\begin{tabular}{cccc}
\hline $\begin{array}{c}\text { Infestasi } \\
\text { STH }\end{array}$ & $\begin{array}{c}\text { Eosinofilia } \\
\mathrm{N}(\%)\end{array}$ & $\begin{array}{c}\text { Tidak } \\
\text { eosinofilia } \\
\mathrm{N}(\%)\end{array}$ & $\mathrm{N}(\%)$ \\
\hline Positif & $13(92,9 \%)$ & $1(7,1 \%)$ & 14 \\
& & & $(100 \%)$ \\
Negatif & $66(100 \%)$ & $0(0 \%)$ & 66 \\
& & & $(100 \%)$ \\
N (\%) & $67(83,8 \%)$ & $13(16,2 \%)$ & 80 \\
& & & $(100 \%)$ \\
\hline
\end{tabular}

Hasil pemeriksaan eosinofil memperlihatkan siswa yang terinfestasi STH sebagian besar mengalami eosinofilia.

Tabel 3. Hubungan antara infestasi STH dan kejadian eosinofilia pada uji Fisher Exact

\begin{tabular}{cccc}
\hline & \multicolumn{2}{c}{ Eosinofilia } & \\
\cline { 2 - 3 } Infestasi STH & Tidak & Ada & Jumlah \\
\hline Negatif & 66 & 0 & 66 \\
Positif & 1 & 13 & 14 \\
& & & \\
\hline Jumlah & 13 & 67 & 80 \\
\hline
\end{tabular}

Berdasarkan uji Fisher Exact diperoleh nilai $P<0,001$. Berdasarkan analisis koefisien korelasi $P$ hi diperoleh $\mathrm{r}=-0,956$ dengan $P<0,001$. Ini berarti terdapat hubungan yang sangat bermakna antara infestasi cacing dan kejadian eosinofilia ( $P$ $<0,001)$.

\section{BAHASAN}

Dari hasil pemeriksaan feses yang dilakukan pada 80 siswa ditemukan 14 siswa $(17,5 \%)$ terinfestasi STH. Dari 14 siswa yang terinfestasi STH, semuanya disebabkan oleh cacing Ascaris lumbricoides. Hasil ini sama dengan penelitian oleh Thomas Gaghana (2012) pada anak-anak komunitas "Dinding” di 
Pasar Bersehati Manado yang mendapatkan bahwa anak yang terinfestasi STH semuanya disebabkan oleh cacing Ascaris lumbricoides. ${ }^{13}$ Penelitian lainnya, antara lain oleh Mardiana dan Djarismawati (2008) pada siswa SD Wajib Belajar Pengentasan Kemiskinan Daerah Kumuh di wilayah DKI Jakarta; Wiguna DY (2008) pada siswa SDN 03 Kecamatan Pringapus; Dachi RA (2005) pada siswa SD NO.174593 Hatoguan di Kecamatan Palipi; dan Ekpenyong et al. (2008), mendapatkan hasil infestasi STH paling banyak disebabkan oleh Ascaris lumbricoides. ${ }^{14-17}$

Berbeda dengan hasil penelitian oleh Astri Maharani P (2005) pada siswa SDN Karang Mulyo 02, Kecamatan Pegadon Kabupaten Kendal, dimana ditemukan infestasi terbanyak disebabkan oleh cacing tambang (Necator americanus dan Ancylostoma duodenale). ${ }^{18}$ Hal ini terjadi karena tempat penelitian tersebut berada di sekitar daerah perkebunan dan persawahan yang biasanya memiliki struktur tanah pasir yang gembur, tercampur humus, dan terlindung dari sinar matahari yang mendukung siklus hidup cacing tambang. Berbeda dengan daerah Buha yang memiliki struktur tanah liat yang mendukung siklus hidup cacing Ascaris lumbricoides dan mungkin daerah ini sudah endemi dengan infestasi Ascaris lumbricoides. Di daerah endemi dengan insiden Ascaris lumbricoides yang tinggi, terjadi penularan secara terus menerus. $^{19}$

Pada siswa yang terinfestasi STH dilakukan pemeriksaan darah untuk mengetahui jumlah eosinofil. Hasil pemeriksaan jumlah eosinofil pada 14 siswa yang terinfestasi STH menunjukkan 13 siswa (92,9\%) terdapat eosinofilia dan hanya 1 siswa yang memiliki jumlah eosinofil normal. Dari hasil penelitian ini dapat diketahui bahwa sebagian besar infestasi STH dapat menyebabkan eosinofilia. Hasil ini sesuai dengan hasil penelitian yang dilakukan oleh Satti Abdulrahim dan Annas Hamdoun (2011) yang mendapatkan hasil adanya eosinofilia pada anak yang terinfestasi cacing Ascaris lumbricoides. ${ }^{20}$ Hasil ini juga sesuai dengan penelitian
Aggarwal B et al. yang menemukan adanya eosinofilia pada studi kasus anak usia 18 bulan. $^{21}$

Berdasarkan uji Fisher Exact dan analisis koefisien korelasi Phi, diketahui adanya hubungan yang sangat bermakna antara infestasi cacing yang ditularkan melalui tanah dan kejadian eosinofilia. Hasil ini berbeda dengan penelitian yang dilakukan oleh Sumagasay JB dan Emverda FM pada siswa Sekolah Menengah Pertama di Sekolah Adat Filipina yang menyatakan bahwa terdapat korelasi sedang antara infestasi STH dengan eosinofilia. ${ }^{7}$ Menurut peneliti, adanya perbedaan hasil ini terjadi karena perbedaan prosedur penelitian. Prosedur penelitian pada penelitian tersebut diawali dengan pemeriksaan eosinofil kemudian dilakukan pemeriksaan feses pada siswa yang terdapat eosinofilia sedangkan pada penelitian ini pemeriksaan eosinofil dilakukan pada siswa yang terinfestasi STH. Adanya eosinofilia pada siswa yang ada infestasi STH merupakan respon imun tubuh terhadap cacing. ${ }^{9}$

Kelemahan pada penelitian ini yaitu tidak dilakukan penelitian mengenai perilaku dan kebiasaan siswa yang bisa memengaruhi insiden infestasi cacing. Selain itu, pada siswa yang tidak terinfestasi cacing tidak dilakukan pemeriksaan eosinofil dan diasumsikan memiliki eosinofil normal.

\section{SIMPULAN}

Infestasi cacing yang ditularkan melalui tanah paling sering disebabkan oleh Ascaris lumbricoides. Terdapat hubungan yang sangat bermakna antara infestasi cacing yang ditularkan melalui tanah dan eosinofilia.

\section{UCAPAN TERIMA KASIH}

Ucapan terima kasih ditujukan kepada para penguji skripsi dan semua pihak baik secara langsung maupun tidak langsung telah menimbulkan ide pada penulis.

\section{DAFTAR PUSTAKA}

1. Zulkoni HA. Parasitologi untuk kepe- 
rawatan, kesehatan masyarakat dan teknik lingkungan. Yogyakarta: Nuha Medika, 2011; p.64.

2. Supriastuti. Infeksi soil-transmitted helminth: ascariasis, trichuriasis, dan cacing tambang. Universa Medicina. 2006; 25(2):85.

3. Sumanto D. Faktor resiko infeksi cacing tambang pada anak sekolah [Tesis]. Program studi magister epidemiologi pasca sarjana: Universitas Diponegoro; 2010.

4. Profil Pengendalian Penyakit dan Penyehatan Lingkungan tahun 2008 [homepage on the Internet]. 2008 [cited 2012 Aug 10]. Available from: www.pppl.depkes.go.id/_asset/_download/ PROFILPP\&PL_2008.pdf.

5. Rengkuan S. Perbandingan efektifitas albendasol dengan pirantel pamoat pada pengobatan infeksi cacing usus yang ditularkan melalui tanah pada anak SD kelas 1 di Kecamatan Tuminting Manado [Tesis]. Program Pendidikan Dokter Spesialis Ilmu Kesehatan Anak: Fakultas Kedokteran Universitas Sam Ratulangi Manado; 2004.

6. Lalandos JL, Kareri DGR. Prevalensi infeksi cacing usus yang ditularkan melalui tanah pada siswa SD GMIM Lahay Roy Malalayang. MKM. 2008; 3(2):86-91.

7. Sumagaysay JB, Emverda FM. Eosinophilia and incidence of soiltransmited helminthic infection of secondary students of an indigenous school. Asian Journal of Health. 2011; 1(1):172-82.

8. Male D, Brostoff J, Roth DB, Roitt I. Immunology, 7th ed. New York: Elsevier, 2006; p.288-90.

9. Baratawidjaja KG, Rengganis I. Imunologi dasar. Edisi VIII. Jakarta: Balai Penerbit FKUI, 2009; p.78-446.

10. Dawson HEE, Greenberg SL, Domachowske, Olson BG. Eosinophilia and the seroprevelence of scistosomiasis and strongyloidasis in newly arrived pediatris Refugees: an examination of centeters for disease control and prevention screening guidelines [Abstract]. J Pediatr. 2010; 156(6):1016-8.

11. Schulte C, Krebs B, Jelienek T,
Nothdurft HD, Von Sonnenburg F, Loscher $\mathbf{T}$. Diagnostic significance of blood eosinophilia in returning travelers. Clin Infect Dis. 2002; 34(3):40-11.

12. Nutman TB. Evaluation and differential diagnosis of marked, persistent eosinophilia. Immunol Allergy Clin North Am [serial online]. 2007 Aug [cited 2012 Aug 16]; 27(3):[1]. Available from: URL:www.ncbi.nih.gov/pmc/articles/PMC 099246/pdf/nihms-32037.pdf.

13. Gaghana TCAP. Profil penyakit infeksi cacing yang ditularkan melalui tanah pada anak-anak Komunitas "Dinding” di Pasar Bersehati Manado. Universitas Sam Ratulangi Manado 2012.

14. Mardiana, Djarismawati. Prevalensi cacing usus pada murid sekolah dasar wajib belajar pelayanan gerakan terpadu pengentasan kemiskinan daerah kumuh di wilayah DKI Jakarta. Jurnal Ekologi Kesehatan. 2008;7(2):769-774.

15. Wiguna DY. Hubungan antara status sosial ekonomi dengan infeksi soil transmitted helminths di SDN 03 Kecamatan Pringapus kabupaten Semarang. Universitas Diponegoro Semarang 2008.

16. Dachi RA. Hubungan perilaku anak sekolah dasar NO.174593 Hatoguan terhadap infeksi cacing perut di Kecamatan Palipi Kabupaten Samosir tahun 2005. Jurnal Mutiara kesehatan indonesia. 2005;1(2):38-40.

17. Ekpenyong, Asuquo E, Eyo, Effiong J. Prevalence of intestinal helminth infection among schooling children in tropical semi urban communities. ARI. 2008;5(1);806.

18. Maharani A. Infeksi nematoda usus pada siswa Sekolah Dasar Negri (SDN) Karang Mulyo 02, Kecamatan Pangadon, Kabupaten Kendal. Jurnal Kedokteran Yarsi. 2005;13(1):24-32.

19. Sutanto I, Ismid IS, Sjarifuddin PK, Sungkar S. Parasitologi kedokteran. Edisi IV. Jakarta: Balai Penerbit FKUI, 2009; p. 5-24.

20. Satti SA, Hamdoun A. Ascaris Lumbricoides in a 13-year old child. Sudan J Paediatr. 2011; 11(1):68.

21. Aggarwal $B$, Sharma $M$, Singh T. Acute eosinophilic pneomonia due to round worm infestation. Indian J Pediatric. 2008; 75:296-7. 